\title{
MODELO DE MEDIAÇÃO ESTRATÉGICA NA EAD COM ALCANCE DE 97\% DE SUCESSO DA OPERAÇÃO
}

\author{
SÃO PAULO/SP ABRIL/2018 \\ Elisete Aparecida Rasera - SENAC - elirasera@gmail.com \\ Rosana Matsushita Assayag - SENAC - rosana@rosanamatsushita.com.br \\ Nayara Alves Carreira - SENAC - nayara.alves87@gmail.com \\ Anderson Antonio da Silva Sirica - SENAC - anderson_sirica@hotmail.com \\ Giovani Santos de Oliveira - SENAC - 1432.giovani@gmail.com \\ Tipo: Relato de Experiência Inovadora (EI) \\ Categoria: Estratégias e Políticas \\ Setor Educacional: EDUCAÇÃO CORPORATIVA
}

\begin{abstract}
RESUMO
Este trabalho apresenta um modelo de mediação estratégica da Operação do Programa Escola de Liderança SENAC - Serviço Nacional de Aprendizagem Comercial - um projeto corporativo de extensão universitária, na modalidade EAD (100\% online), realizado no período de outubro de 2016 a março de 2018, para líderes do primeiro escalão da Instituição, com abrangência em todo o território nacional. O Programa foi estruturado em trilhas de aprendizagem, composto por 6 cursos integrados, para atender a líderes de unidades educacionais e líderes administrativos e operacionais, visando a sua atuação como profissionais capazes de gerar sustentabilidade, inovação, integração, colaboração e otimização do trabalho educacional. A orientação metodológica para a realização da mediação desse Programa foi baseada na ação-reflexão-ação, a partir de uma estrutura organizacional horizontal da Operação e de um sistema de comunicação centrado diretamente no aluno. A dinâmica de atuação da equipe de mediação foi baseada no planejamento, na execução e no monitoramento das ações, permeada por um sistema de comunicação eficaz e organizada da seguinte forma: a tutoria na comunicação, os docentes no pedagógico e a coordenação na gestão operacional e nas parcerias internas e externas. Como resultado, o Programa chegou a alcançar $97 \%$ de sucesso da Operação.
\end{abstract}

Palavras-chave: mediação, EAD, projeto corporativo, operação, comunicação 


\section{Introdução}

Este artigo apresenta um relato de experiência inovadora na categoria estratégias e políticas, referente a um projeto de educação corporativa e tem como objetivo apresentar um modelo de mediação estratégica que foi desenvolvido para a Operação do Programa Escola de Liderança SENAC - Serviço Nacional de Aprendizagem Comercial. Trata-se de um programa de extensão universitária na modalidade EAD, $100 \%$ online, destinado a líderes do primeiro escalão que atuam em unidades educacionais distribuídas em todo o país e realizado no período de outubro de 2016 a março de 2018. O Programa foi estruturado a fim de capacitar líderes táticos de unidades educacionais e líderes de áreas administrativas e operacionais, visando o desenvolvimento de competências, por meio de 6 cursos integrados, com seus diferentes olhares: (1) Curso Excelência no Trabalho (ET): olhar para o dia-a-dia; (2) Curso Orientação para Inovação (OI): olhar para o futuro; (3) Curso Atuação Integrada (AI): olhar para fora; (4) Liderança e Gestão de Pessoas (LGP): olhar para dentro; (5) Curso Gestão de Projetos (GP): olhar o todo - início, meio e fim; (6) Curso Gestão da Educação Profissional (GEP): olhar para o core business.

O Programa foi estruturado em quatro trilhas de aprendizagem:

Público: Líderes de Unidades Educacionais $>>$ Trilha $\mathrm{A}=\mathrm{ET}>\mathrm{OI}>\mathrm{Al}>\mathrm{LGP}>\mathrm{GP}>$ GEP $\|$ Trilha $\mathrm{B}=\mathrm{OI}>\mathrm{ET}>\mathrm{LGP}>\mathrm{Al}>\mathrm{GEP}>\mathrm{GP}$

Público: Líderes Administrativos e Operacionais $>>$ Trilha $A=E T>O I>A I>L G P>G P$ II Trilha $\mathrm{B}=\mathrm{OI}>\mathrm{ET}>\mathrm{LGP}>\mathrm{Al}>\mathrm{GP}$

E dividido em três fases e, em cada fase, foram ofertados dois cursos simultaneamente:

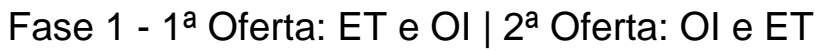

Fase 2 - 1a Oferta: Al e LGP | 2ª Oferta: LGP e Al

Fase 3 - 1을 Oferta: GP e GEP | $2^{\text {a }}$ Oferta: GEP e GP

Um dos maiores desafios na implantação deste projeto corporativo foi constituir uma equipe de mediação - composta por coordenação, tutores e docentes, orientada por uma filosofia de trabalho baseada nas seguintes diretrizes:

- garantia do sucesso do Programa e da Operação, assegurando os indicadores de desempenho, a imagem da Instituição e do cliente;

- postura profissional proativa, sinérgica, gentil e alinhada, sempre buscando a qualidade e a prontidão nas devolutivas aos alunos; 
- ênfase em despertar no aluno a participação efetiva para que o ambiente virtual fosse um meio de facilitar a troca de experiências e a apresentação das melhores práticas desenvolvidas em sua unidade, para os demais colegas espalhados em todo o Brasil.

- a experiência da coordenação da equipe de mediação com uma filosofia de trabalho que privilegia a relação horizontal na gestão de pessoas, tendo como foco o aluno. Com isso, sempre desafiava a equipe a refletir sobre: "Qual é o nosso enfoque?"; "Qual é a nossa postura?"; "Qual é a nossa diretriz?”; "Quais são as características do nosso desafio?"; "De que forma a equipe será avaliada?"; "Qual é o nosso sistema de comunicação?", sempre alinhado no programa de ação.

Inspirados em uma forma de trabalhar baseada na ação-reflexão-ação e com uma visão de conjunto de todo o Programa, em nenhum momento houve distinção, prioridades ou privilégios entre esses profissionais, pois o foco no resultado era o objetivo de todos. Com o espírito de contribuição e cooperação sempre aguçado, além de muita proatividade, houve, gradativamente, a construção de uma sintonia entre os componentes da equipe, culminando em uma boa sinergia dos trabalhos, o que fez toda a diferença ao longo do processo e no alcance dos resultados. O sistema de comunicação adotado foi o grande mote do sucesso da operação desse programa, que teve na tutoria um papel estratégico, pois ela tinha o caráter permanente, ou seja, acompanharia os alunos nas trilhas de aprendizagem até o final do programa, enquanto que os professores, em caráter transitório, eram renovados por especialidade, a cada novo curso. Para manter a continuidade e linearidade da filosofia implantada na operação do Programa, estrategicamente um professor de cada trilha permanecia na equipe de mediação para transmitir aos novos professores o histórico de cada curso e, juntamente com a tutoria, realizavam capacitações aos novos docentes. O desafio do Programa era garantir a permanência deste público, com mais de 600 alunos espalhados por todo o Brasil, utilizando um ambiente de aprendizagem 100\% online, de forma ativa e colaborativa, no período de um ano e meio. Além disso, existia a expectativa de que os líderes (alunos do Programa) trocassem experiências e compartilhassem as melhores práticas. Um público com perfil bastante heterogêneo, com especificidades regionais, cada qual compartilhando a sua realidade. Além disso, modificações estruturais e significativas logo no início do Programa, quando atividades avaliativas deixaram de ser obrigatórias e passaram a ser optativas, impactaram o plano de mediação existente, havendo a necessidade de recriar toda a forma de atuação da equipe com o intuito de manter acesa a chama desses alunos, atender a essa nova demanda e alcançar os resultados pactuados. Uma rotina de trabalho foi sistematizada a partir da elaboração de agendas, sendo que a da tutoria estava focada na comunicação, 
a do docente no pedagógico e, a da coordenação na gestão operacional, nas parcerias estratégicas e nos apoios. De tal forma que todas as ações estavam voltadas diretamente ao aluno. $O$ trabalho docente se desenvolveu focado no pedagógico, nos conteúdos de cada curso, na interação ao vivo por meio de webconferências semanais, no acompanhamento e gestão da sua turma de alunos. Neste último, contava-se com a equipe de tutoria que gerava relatórios extraídos pela plataforma, bem como elaborava outras informações que alimentava o processo de gerenciamento do alunado.

Isso posto, a questão de pesquisa que se pretende responder é: como um modelo de mediação estratégica pode impactar o sucesso da operação e os resultados de um programa EAD? E é exatamente com esse objetivo que o presente artigo pretende responder esta pergunta, por meio deste relato de experiência que traz o case de uma instituição com mais de 70 anos dedicados à educação no Brasil e com abrangência em todo território nacional.

\section{Objetivo}

O objetivo deste trabalho consiste em apresentar um modelo de mediação estratégica de operação para EAD com foco no engajamento e na permanência dos alunos para alcançar um elevado percentual de sucesso da Operação.

\section{Referencial teórico}

Este artigo apresenta um relato de experiência com base em vivências da equipe de mediação de um projeto corporativo, conforme YIN (2015) referenda o estudo de caso como método de pesquisa, pois "é usado em muitas situações, para contribuir ao nosso conhecimento dos fenômenos individuais, grupais, organizacionais, sociais, políticos e relacionados" (Yin, 2015, p.4).

\footnotetext{
"Em resumo, um estudo de caso permite que os investigadores foquem um "caso" e retenham uma perspectiva holística e do mundo real - como um estudo dos ciclos individuais da vida, o comportamento dos pequenos grupos, os processos organizacionais e administrativos, a mudança de vizinhança, o desempenho escolar, as relações internacionais e a maturação das indústrias" (Yin, 2015, p.4)
}

Essas vivências também foram inspiradas na experiência da coordenação da equipe com uma filosofia de trabalho que privilegia a relação horizontal na gestão de pessoas, tendo como foco o aluno. O enfoque, a diretriz, a postura dos envolvidos, as características do desafio e as formas de avaliação da equipe estavam sempre alinhados no programa de ação. Os alinhamentos e (re)definições eram feitos no início de cada nova etapa. 
Conforme a economista e coordenadora da Operação do Programa, se fazia necessária a mensuração de indicadores, como o percentual de sucesso da Operação[1], percentual de desperdício de vagas[2] e percentual de sucesso do Programa[3] entre outros, para monitorar os resultados e nortear todo o trabalho da equipe de mediação.

A orientação metodológica para a realização da mediação desse Programa foi baseada na ação-reflexão-ação, ou seja, refletir sobre o que é feito enquanto é feito (Schön, 2007) e (re)planejar novas ações.

\section{Procedimentos metodológicos}

Toda a Operação do Programa foi inspirada por uma filosofia de trabalho que preconizou uma gestão democrática, o trabalho em equipe e a sinergia entre os pares, e se apoiou em um sistema de comunicação contundente que teve início desde o processo seletivo da equipe de mediação até a conclusão do Programa como um todo.

Como a Equipe de Mediação funcionava: o planejamento era elaborado em conjunto, a execução das ações planejadas era delegada à docentes e tutores, e o monitoramento era realizado pela tutoria, em alinhamento com os docentes que fazia 0 acompanhamento das turmas e a Coordenação na gestão operacional do Programa.

Com um planejamento conjunto, estratégias de ação bem definidas e clareza no papel que cada um iria desempenhar ao longo de sua atuação, a base estava na inovação constante, pois não havia um roteiro engessado, mas uma estrutura flexível que poderia ser modificada e as ações redefinidas, quando uma determinada ação atingia seu grau de saturação. E como isso era percebido? Por meio de um monitoramento constante, baseado em dados qualitativos e quantitativos, num diálogo permanente entre docentes, tutores e coordenação, identificando pontos de melhoria, a fim de atingir o sucesso da operação.

E como isso foi possível? As principais ações realizadas foram:

- Inversão da Estrutura Hierárquica da Operação: de vertical para horizontal, pois esse tipo de estrutura permite maior flexibilidade e agilidade ao implementar e adequar estratégias, gerando mais velocidade no atendimento, de forma personalizada, às demandas dos alunos. Assim, a tutoria 'sai da linha' de subordinação ao professor e passa a ser apoio, deixa de ter a visão micro para uma visão macro, visualizando o programa como um todo e, nesse sentido, assume um papel estratégico dentro do processo, em parceria com os docentes. 
- Criação de um Sistema de Comunicação: esse foi o ponto fundamental que norteou toda a estratégia para alcançar o resultado. Algumas ações que foram realizadas para atender bem esse alunado: contato com os Representantes Estaduais - profissionais indicados por cada Estado para ser a interface entre a coordenação e os alunos; aproximação física no espaço de trabalho entre coordenador, professores e tutores para dar maior fluidez à comunicação; preocupação da equipe em se colocar no lugar do aluno e procurar entender se a forma e/ou meio escolhidos para se comunicar seriam os mais adequados para o entendimento e atendimento do aluno lá na ponta.

- Desenvolvimento de um plano de comunicação com o aluno: a diretriz desse plano teve como pano de fundo uma linguagem assertiva, objetiva e clara, com ênfase na gentileza. Foi implementado a partir da estratégia e definição de ações que, conforme dito anteriormente, atingia seu grau de saturação em determinado momento, daí sua estrutura também mudava à medida que as ações eram redefinidas. Por exemplo, os avisos que eram apresentados em textos longos, foram modificados para textos mais curtos e, depois, incluídos vídeos, imagens e gif., assim como, as webconferências, que eram realizadas em laboratórios e passaram a ser em formato painel, de maneira mais dinâmica e interativa. Houve a padronização da linguagem com base na cultura da Instituição e do cliente, tanto nos avisos (cores do Programa e da instituição), quanto nos slides das webconferências, bem como na criação de uma rotina de comunicados semanais.

Essa mesma linha de pensamento também foi reproduzida na interação nos fóruns de discussão, tanto de dúvidas quanto temáticos, bem como no envio de e-mails, contatos telefônicos e/ou mala direta. Vale ressaltar que todas essas ações estão pautadas numa abordagem assertiva, gentil, prezando o cuidado com o tom da linguagem/comunicação com alunos, por meio de todos esses canais, com ênfase na importância da parceria.

Essa mesma postura era considerada na análise e feedback dos professores nas atividades avaliativas, com devolutivas cirúrgicas - precisas, sem deixar margens para interpretações ambíguas -, de maneira focada, sem rodeios, dando as devidas orientações, mas com gentileza. Por isso a importância do exercício de inversão de papéis, ter a preocupação de se colocar no lugar do aluno pensando em melhorar a comunicação e a interação com o mesmo.

Outra forma de comunicação com os alunos foi a criação do Guia Prático, um material com orientações básicas e calendário de cada curso, que era disponibilizado aos Representantes de cada Estado com objetivo que entregassem aos seus alunos, a fim de estreitar o relacionamento entre eles. 
- Definição de Papéis e atuação da Equipe de Mediação: o planejamento das ações era realizado a partir de uma construção coletiva, quando era definido o papel de cada integrante da equipe de mediação e, por isso, a execução era delegada, para ser aplicada com a devida autonomia, de forma sinérgica e compartilhada. Em seguida, o monitoramento era feito pela tutoria, que abastecia a coordenação e os professores de informações quantitativas e qualitativas, para que pudessem fazer a gestão das turmas, bem como redirecionar as ações, sempre que necessário, com vistas a garantir o sucesso da operação.

Dessa maneira, os papéis foram assim definidos:

1. Corpo Docente: responsável pela parte pedagógica do curso, por trilhas de aprendizagem, interação nos fóruns temáticos, realização de webconferências, orientação e correção das atividades avaliativas e gestão da turma baseada em relatórios gerenciais de monitoramento. O olhar de gestor do professor, aliado a sua atuação proativa no processo de interação com os alunos, interferiu diretamente nos resultados de seus desempenhos.

2. Tutoria: responsável pela execução do plano de comunicação, em alinhamento com o corpo docente e coordenação, a fim de levar aos alunos uma forma de comunicação atrativa e engajadora, com foco no resultado esperado. Atuou fortemente no monitoramento durante a mediação do Programa, elaborando relatórios de acompanhamento, qualitativos e quantitativos, a partir dos resultados de pesquisas, enquetes, extratos do AVA (entregas de atividades avaliativas; controle de acesso dos alunos ao ambiente); realizando 'varredura' nos fóruns de discussão para verificar se a interação entre professores e alunos nos fóruns estava de acordo com a filosofia de trabalho; verificando as devolutivas/feedbacks dos professores aos alunos nas atividades avaliativas, por amostragem; entre outros.

3. Coordenação da Equipe de Mediação: responsável pela interface entre a coordenação geral EAD e a equipe de mediação. Atuou no Programa como um todo, coordenando e orientando o corpo docente e a tutoria, realizando a gestão operacional do Programa, além de atender as demandas dos Representantes dos Estados. Com uma filosofia de gestão democrática, reunia a equipe e definia em conjunto o planejamento das ações a serem executadas, sempre baseada em informações gerenciais (quantitativas e/ou qualitativas) - resultados de enquetes, amostragens de devolutivas nos fóruns dos professores, extração de relatórios da plataforma, reunião com os parceiros, Representantes dos Estados, reuniões diretas, diárias e rápidas com a equipe de mediação, ou seja, uma gestão de 
portas-abertas, sempre disponível a ouvir a demanda da equipe.

- Realização de Parcerias: outro ponto-chave do sucesso da operação foi o estabelecimento de parcerias:

1. Alianças Estratégicas: com Representantes dos Estados, que eram em sua maioria, profissionais da área de Recursos Humanos/Educação Corporativa e tinham uma interface muito forte com a coordenação da equipe de mediação, estreitando ainda mais a comunicação com o aluno, melhorando o atendimento de suas demandas.

2. Alunos-Destaque: os alunos que se destacavam ao longo dos cursos, eram convidados a participar das webconferências para apresentar seu Trabalho de Consolidação da Aprendizagem (TCA) e compartilhar as melhores práticas.

3. Apoios Internos: equipes administrativas e de suporte do Senac que davam apoio necessário à execução da Operação.

- Gestão da equipe: a avaliação e o feedback da coordenação aos membros da equipe de mediação eram feitos baseados na relação $70 / 30$, considerando $70 \%$ do trabalho realizado em equipe e $30 \%$ individualmente, favorecendo o desenvolvimento de habilidades e competências, tanto individuais, como coletivas.

- Monitoramento dos alunos: permeava o ciclo de todas as ações e redefinia os novos planos e papéis, antes de atingir o ponto de saturação. Todas as ações realizadas pela equipe de mediação passavam pelas etapas de planejamento, execução e avaliação. O monitoramento era feito em cada uma dessas etapas e alimentava novas tomadas de decisões e novos encaminhamentos.

- Momentos síncronos de interatividade: são momentos de interação em tempo real, dentro da plataforma virtual, entre professores e alunos, com situações provocativas para a troca de experiências e de construção de novas aprendizagens, instigando a exposição de ideias, momento único e oportuno de interação ao vivo. Eram realizados via webconferência e representou uma das iniciativas que mais evoluiu em termos de inovação durante o desenvolvimento do programa, partindo de um modelo tradicional de videoaula, para um formato painel, permitindo o exercício do protagonismo do aluno, ao convidá-lo para expor suas melhores práticas. Além disso, esses momentos foram enriquecidos com a participação de palestrantes que apresentaram temas complementares às unidades de estudo.

Outro momento que marcou a evolução deste processo foi a realização da 
webconferência integrada, onde 0 aluno, independente da trilha de aprendizagem, tinha a possibilidade de participar da web do curso que acontecia de forma paralela.

Por último, foi criada a 'Web Coffee', que acontecia no intervalo das webconferências com o intuito de trazer assuntos transversais às temáticas dos cursos, em formato de entrevistas rápidas com os professores e mediação da tutoria, em momento de maturidade da equipe de mediação.

\section{Apresentação e discussão dos resultados}

Este artigo apresentou as principais ações realizadas na construção de um modelo de mediação estratégica de operação para EAD, tendo como principal foco o engajamento e a permanência dos alunos, para alcançar um elevado percentual de sucesso no resultado da Operação. $O$ resultado foi balizado pelo percentual de sucesso da Operação que consiste no número de alunos aprovados pelo número de alunos inscritos menos os alunos cancelados e os que nunca acessaram a plataforma:

\% Sucesso da Operação $=($ alunos aprovados $) /($ inscritos - alunos cancelados - sem acesso)

Trocando em miúdos, o aluno 'colocou a cara' no ambiente virtual, ele é 'seu', ou seja, é responsabilidade da Operação mantê-lo engajado e ativo no processo de ensinoaprendizagem. Para efeito deste artigo, a ênfase será dada neste indicador, entretanto, existem outros já mencionados, como percentual de desperdício de vaga e sucesso do Programa, entre outros.

Portanto, o resultado da Operação em cada oferta foi:

Fase 1 - $1^{\underline{a}}$ oferta: Excelência no Trabalho e Orientação para Inovação = 92\% 2ª oferta: Orientação para Inovação e Excelência no Trabalho = 95\%

Fase 2 - 1를 oferta: Atuação Integrada e Liderança e Gestão de Pessoas $=97 \%$ 2ª oferta: Liderança e Gestão de Pessoas e Atuação Integrada $=96 \%$ Fase 3 - 1ํㅡㄹ oferta: Gestão de Projetos e Gestão Educação Profissional $=97 \%$ 2ª oferta: Gestão Educação Profissional e Gestão de Projetos = 96\%

\section{Considerações Finais}

Diante do exposto ao longo deste artigo, conclui-se que, a resposta para o desafio proposto na introdução deste trabalho foi dada com os números apresentados, mostrando que, de fato, o modelo de mediação estratégica impacta no sucesso da 
Operação e nos resultados de um programa EAD, culminando no percentual alcançado de $97 \%$.

O sucesso da Operação esteve centrado no planejamento coletivo, na execução por delegação e autonomia da equipe de mediação, e no monitoramento constante das ações, permeado por um sistema de comunicação eficaz.

Ao escolher uma metodologia de trabalho que preconiza uma gestão democrática, apoiada neste sistema de comunicação, mantendo uma linearidade na filosofia de trabalho implantada, focada no aluno, com uma equipe de mediação proativa, sinérgica, gentil e alinhada ao planejamento, execução e monitoramento do Programa como um todo, foram alcançados patamares inéditos da EAD, com o elevado percentual de sucesso no resultado da Operação.

\section{Referências}

SCHIMITT, M. A. Ação-Reflexão-Ação: A Prática Reflexiva como elemento transformador do cotidiano educativo. Protestantismo em Revista, São Leopoldo, RS, v. 25, maio-ago 2011. Disponível em: http://periodicos.est.edu.br/index.php/nepp/article/view/157/194, acesso em 21 de abr 2018, às $17 \mathrm{~h} 50$.

SCHÖN, D. A. Educando o profissional reflexivo [recurso eletrônico]: um novo design para o ensino e a aprendizagem. Tradução Roberto Cataldo Costa. Porto Alegre: Artmed, 2007.

SERVIÇO NACIONAL DE APRENDIZAGEM COMERCIAL - SENAC. Plano de Curso Extensão Universitária - Programa Escola de Liderança SENAC - Líderes Táticos da Área Educacional. São Paulo, 2017.

YIN, R.K. Estudo de Caso: Planejamento e Métodos. 5. ed. Porto Alegre: Bookman, 2015.

[1] Considera-se Sucesso da Operação os alunos aprovados pelo número de alunos inscritos menos os alunos cancelados e os que nunca acessaram a plataforma.

[2] Refere-se aos alunos que não participaram do curso (cancelados + sem acesso) pelos alunos matriculados.

[3] Números de aprovados pela quantidade de vagas assumidas, incluindo os alunos que nunca acessaram a plataforma e os cancelados. 